\title{
Fear of falling in community-dwelling older adults presenting to the emergency department for minor injuries: Impact on return to the ED and future falls
}

\author{
Marie-Pier Lanoue (1), MDCM, PGY4*; Marie-Josée Sirois, PhD*; Jeffrey J. Perry, MD, MSc; \\ Jacques Lee, MD, MSc ${ }^{\S}$; Raoul Daoust ${ }^{0}, \mathrm{MD}, \mathrm{CSPO}, \mathrm{MSc}$; Andrew Worster, MD, MSc ${ }^{* *}$; \\ Sandrine Hegg, PhD ${ }^{\dagger}$; Pierre-Hugues Carmichael ${ }^{\dagger+}$; Audrey-Anne Brousseau-Turcotte, MD, MSc ${ }^{\ddagger \neq}$; \\ Marcel Émond (1), MD, MSc ${ }^{* \dagger}$
}

\begin{abstract}
CLINICIAN'S CAPSULE
What is known about the topic?

Fear of falling is common in older emergency department

(ED) patients and is associated with decreased mobility.

What did this study ask?

Is fear of falling associated with return to the ED and future falls in community-dwelling older patients following a minor trauma?

What did this study find?

Fear of falling is associated with subsequent falls at 3 and 6 months following a minor trauma.

Why does this study matter to clinicians?

Patients with fear of falling can be identified and oriented towards the appropriated post-ED resources to decrease the risk of bad outcomes.
\end{abstract}

\section{ABSTRACT}

Objectives: 1) To characterize mild, moderate, and severe fear of falling in older emergency department (ED) patients for minor injuries, and 2) to assess whether fear of falling could predict falls and returns to the ED within 6 months of the initial ED visit.

Methods: This study was part of the Canadian Emergency and Trauma Initiative (CETI) prospective cohort (2011-2016). Patients ages $\geq 65$, who were independent in their basic daily activities and who were discharged from the ED after consulting for a minor injury, were included. Fear of falling was measured by the Short Falls Efficacy Scale International (SFES-I) in order to stratify fear of falling as mild (SFES-I =78/28), moderate (SFES-I=9-13/28), or severe (SFES-I=14-28/ 28). Many other physical and psychological characteristics where collected. Research assistants conducted follow-up phone interviews at 3 and 6 months' post-ED visit, in which patients were asked to report returns to the ED.

Results: A total of 2,899 patients were enrolled and 2,009 had complete data at 6 months. Patients with moderate to severe fear of falling were more likely to be of ages $\geq 75$, female, frailer with multiple comorbidities, and decreased mobility. Higher baseline fear of falling increased the risk of falling at 3 and 6 months (odds ratio [OR]-moderate-fear of falling: 1.63, $p<$ 0.05 , OR-severe-fear of falling 2.37, $p<0.05$ ). Fear of falling positive predictive values for return to the ED or future falls were $7.7 \%$ to $17 \%$.

Conclusion: Although a high fear of falling is associated with increased risk of falling within 6 months of a minor injury in older patients, fear of falling considered alone was not shown to be a strong predictor of return to the ED and future falls.

\section{RÉSUMÉ}

Objectifs: L'étude visait 1) à caractériser le degré de crainte de chute : faible, modéré ou élevé, chez les personnes âgées traitées au service des urgences (SU) pour des blessures légères; 2) à déterminer si la crainte de chute constituait un facteur prévisionnel de chute ou de nouvelles consultations au SU dans les 6 mois suivant la consultation initiale.

From the *Faculté de Médecine, Université Laval, Québec City, QC; ${ }^{\dagger}$ Centre de recherche soins et services de première ligne de I'Université Laval, $\mathrm{CHU}$ de Québec-Université Laval Research Center, Université Laval, Québec City, QC; ${ }^{\ddagger}$ Department of Emergency Medicine, University of Ottawa, Ottawa, ON; ${ }^{\S}$ Schwartz/Reisman Emergency Medicine Institute, Toronto, ON; ${ }^{\top}$ Hôpital du Sacré-Cœur de Montréal Research Center, Université de Montréal, Montréal, QC; ${ }^{* *}$ Emergency Medicine, McMaster University, Hamilton, ON; ${ }^{\dagger \dagger}$ Centre d'excellent sur le vieillissement de Québec, QC; and the ${ }^{\ddagger \neq}$ Centre Hospitalier Universitaire de Sherbrooke, Sherbrooke, OC.

Correspondence to: Dr. Marie-Pier Lanoue, Laval Université Québec, 2829 Chemin Saint-Louis, app 21 Québec, QC G1W 1P1;

Email: marie-pier.lanoue.1@ulaval.ca.

(c) Canadian Association of Emergency Physicians 2020

CJEM 2020;22(5):692-700

DOI $10.1017 /$ cem.2020.383 
Méthode: L'étude dont il est question ici a été réalisée dans le cadre de I'Initiative canadienne d'urgence et de traumatologie (2011-2016), une étude de cohorte, prospective. Étaient retenus les patients âgés de $\geq 65$ ans, autonomes dans leurs activités courantes de la vie quotidienne, qui avaient obtenu leur congé du SU après avoir été traités pour des blessures légères. Le degré de crainte de chute a été mesuré sur l'échelle abrégée Short Falls Efficacy Scale International (SFES-I) : faible (7-8/28), modéré (9-13/28) ou élevé (14-28/28). Beaucoup d'autres données sur des caractéristiques physiques et psychologiques ont été recueillies. Les assistants à la recherche ont aussi effectué des entretiens de suivi au téléphone avec les patients, 3 mois et 6 mois après la première consultation au SU, leur demandant s'ils avaient consulté de nouveau au SU.

Résultats: Au total, 2899 patients ont été recrutés, et l'équipe disposait de données complètes sur 2009 d'entre eux au bout de 6 mois. Les patients ayant un degré modéré ou élevé de crainte de chute étaient principalement des femmes âgées de $\geq 75$ ans, fragiles, souffrant de plusieurs maladies concomitantes et ayant une mobilité réduite. Un degré élevé de crainte de chute au départ était associé à une augmentation du risque de chute au bout de 3 mois et de 6 mois (risque relatif approché [RRA] : degré modéré de crainte : 1,63; $p<0,05 ;$ RRA: degré élevé de crainte $: 2,37 ; p<0,05)$. Les valeurs prévisionnelles positives de crainte de chute à l'égard de nouvelles consultations au SU ou d'éventuelles chutes variaient de $7,7 \%$ à $17 \%$.

Conclusion: Bien qu'un degré élevé de crainte de chute soit associé à un risque accru de chute dans les 6 mois suivant la survenue de blessures légères chez les personnes âgées, la crainte de chute en soi ne s'est pas révélée un facteur prévisionnel important de nouvelles consultations au SU ou d'éventuelles chutes.

Keywords: Community-dwelling elderly, emergency, fall, fear of falling

\section{INTRODUCTION}

According to the World Health Organization, a third of people ages $\geq 65$ years fall every year, and this number increases to $50 \%$ in those over 85 years old. ${ }^{1}$ Falls remain the leading mechanism of injury-associated death, and the third leading cause of poor health among older patients. ${ }^{2}$

In 2018, older Canadians made 2.5 million emergency department (ED) visits, ${ }^{3} 25 \%$ of which were the result of a fall. ${ }^{3,4}$ Our team showed that around $80 \%$ of minor injuries among older patients discharged from Canadian EDs were fall-related. ${ }^{5}$ ED-visits by older patients are considered important opportunities for preventing future falls and injuries by identifying high-risk patients. ${ }^{4}$ This appears crucial as $15 \%$ to $20 \%$ fall rates and $30 \%$ unplanned ED returns at 6 months' post-ED visits are reported. ${ }^{6,7}$

Fear of falling was first described as part of a post-fall syndrome in the 1980s and was considered a result of psychological distress following a fall. ${ }^{8}$ It has since been recognized as an important health issue among older adults. ${ }^{9}$ According to various definitions, the prevalence of fear of falling is approximately $40 \%-$ $50 \%,{ }^{10}$ with wide ranges being reported from $12 \%-$ $65 \%$ in community-dwelling non-fallers and from $29 \%-92 \%$ in seniors having already sustained falls. ${ }^{8,10,11}$ Fear of falling can initially be protective by increasing caution in daily activities ${ }^{12}$ but could become detrimental when causing restrictions in activities and result in deconditioning. ${ }^{9}$ Hence, fear of falling after a fall was shown to be a significant risk factor for subsequent ED-visits for repeated falls ${ }^{13,14}$ and for physical, mental, and quality of life decline in older adults. ${ }^{15}$ The 2013 Geriatric Emergency Department Guideline recommends that every older patient presenting to the ED after a fall should undergo a comprehensive assessment of comorbidities and risk factors in order to prevent further injuries and subsequent falls. ${ }^{16}$ Since fear of falling is associated with increased risk of repeated ED visits, falls, and of declining health, identification of fear of falling through proper evaluation could be a contributing factor to older ED patient outcomes.

The main objectives of this study were to 1 ) characterize patients with mild, moderate, and severe fears of falling and 2) assess whether fear of falling could predict subsequent falls and returns to the ED within 6 months of the initial ED-visit for a minor injury. The secondary objective was to explore the possible association between fear of falling and specific causes of return to the ED, such as medical causes and traumatic causes.

\section{METHODS}

\section{Study design}

This is a planned secondary analysis of the Canadian Emergency and Trauma Initiative (CETI), ${ }^{5}$ a multicentre 
prospective cohort study $(\mathrm{N}=3,350)$ conducted between 2011 and 2016 in six university-affiliated EDs (Quebec City, Montreal, Ottawa, Toronto, Hamilton, and Calgary). Full protocol details were previously reported. ${ }^{3,13}$

\section{Study setting and population}

Community-dwelling older patients were included if they were ages $\geq 65$, independent in all activities of daily living (ADLs) (see measures below), and presented to a participating ED with chief complaints of minor injury (i.e., not requiring admission/surgery) sustained in falls. Hospitalized patients and those unable to give consent or to speak French or English were excluded.

Eligible patients were identified by emergency physicians or research staff 24 hours/day, 7 days/week. In-person (for patients presenting to the ED during research staff office hours) or telephone interviews were conducted by trained research assistants within 72 hours of the ED visit. An in-person assessment of the participants' physical condition (functional, mobility, and frailty status) was conducted during the in-person interview. In order to minimize loss to follow-up, the study's steering committee determined that a hybrid combination of in-person and phone interviews at 3 and 6 months would be conducted.

\section{Study measures}

Fear of falling was assessed using the Short Falls Efficacy Scale-International (SFES-I). ${ }^{17}$ This validated tool assesses how concerned older adults are about falling when performing seven daily activities (getting dressed/undressed, taking a bath/shower, getting in/out of a chair, going up/down stairs, reaching for something above the head or on the ground, walking up/down a slope, going out to social events). Each component is rated from 1 (not concerned) to 4 (severe concern). Total scores range from 7 (not concerned) to 28 (most severe concern) and are interpreted by stratifying the scores into three categories: mild (7-8), moderate (9-13), and severe fear of falling (14-28). ${ }^{17}$ Participants were questioned regarding any subsequent falls that might have occurred following their initial ED visit at the 3-and 6-month follow-ups. Participants were asked if they "had fallen hard enough to feel pain afterwards" $(y e s / n o)^{18}$ and the number of falls they had sustained if they answered yes.
Returns to the ED were also self-reported during both follow-up interviews, in which participants were asked if they had consulted to the ED (yes/no) in the past 3 months, and the number of times they did. Medical files of patients returning to the ED at Hopital de l'Enfant-Jésus were analysed to assess the causes of return to the ED (medical or traumatic).

We collected demographic data, including age and sex. Self-reported comorbidities were recorded (yes/no) using a list of 18 physical $^{19}$ (e.g., cardiac, neurological diseases) or psychological conditions (i.e., anxiety, depression, irritability) that may have an impact on the participants' function. ${ }^{19}$ The Identification of Seniors at Risk (ISAR) ED screening tool was used at the index ED-visit. ISAR $\geq 2 / 6$ reflects needs for further geriatric evaluation. $^{20}$ The 2005-Abbreviated Injury Scale ${ }^{21}$ codes were used to compute the Injury Severity Score (ISS), which ranges from 1 (minor) to 75 (unsurvivable). ${ }^{21}$ ISS values $\leq 8$; 9-15; and $\geq 16$ reflect minor, moderate, and severe trauma, respectively. ${ }^{21,22}$

Patients' functional status was measured using the validated Older Americans Resources Services (OARS) scale, which aims to assess a patient's ability to perform seven basic ADLs (eating, grooming, dressing, transferring, walking, bathing, continence) and seven instrumental ADLs (meal preparation, homemaking, shopping, using transportation, using the phone, managing medication, and money). ${ }^{23,24}$ The total OARS score ranges from 0 (dependent) to 28 (independent). Basic mobility was assessed by the Timed "Up-and-Go" (TUG), during which patients are asked to stand up, walk 3 meters away from their chairs, turn around, walk back to their chairs and sit down. The amount of time that each participant takes to perform these tasks was recorded by a research assistant. Participants' mobility status is then considered as free (TUG $<10$ seconds), mostly independent $(<20$ seconds), variable (20-29 seconds), and impaired (> 30 seconds). The TUG was shown to predict functional decline in older patients with minor injuries. ${ }^{25}$ The Study of Osteoporotic Fractures $(\mathrm{SOF})^{26}$ index was used to determine frailty status of the patients. Higher SOF scores are associated with functional decline in older ED patients presenting with minor injuries. ${ }^{5}$ Cognitive impairment was evaluated in-person with the Montreal Cognitive Assessment (MoCA) ${ }^{27}$ or by the Telephone Interview for Cognitive Status-modified (TICS-m) ${ }^{28}$ with respective cut-offs of $<23 / 30$ and $\leq 32 / 50$ for cognitive impairments. ${ }^{26}$ 


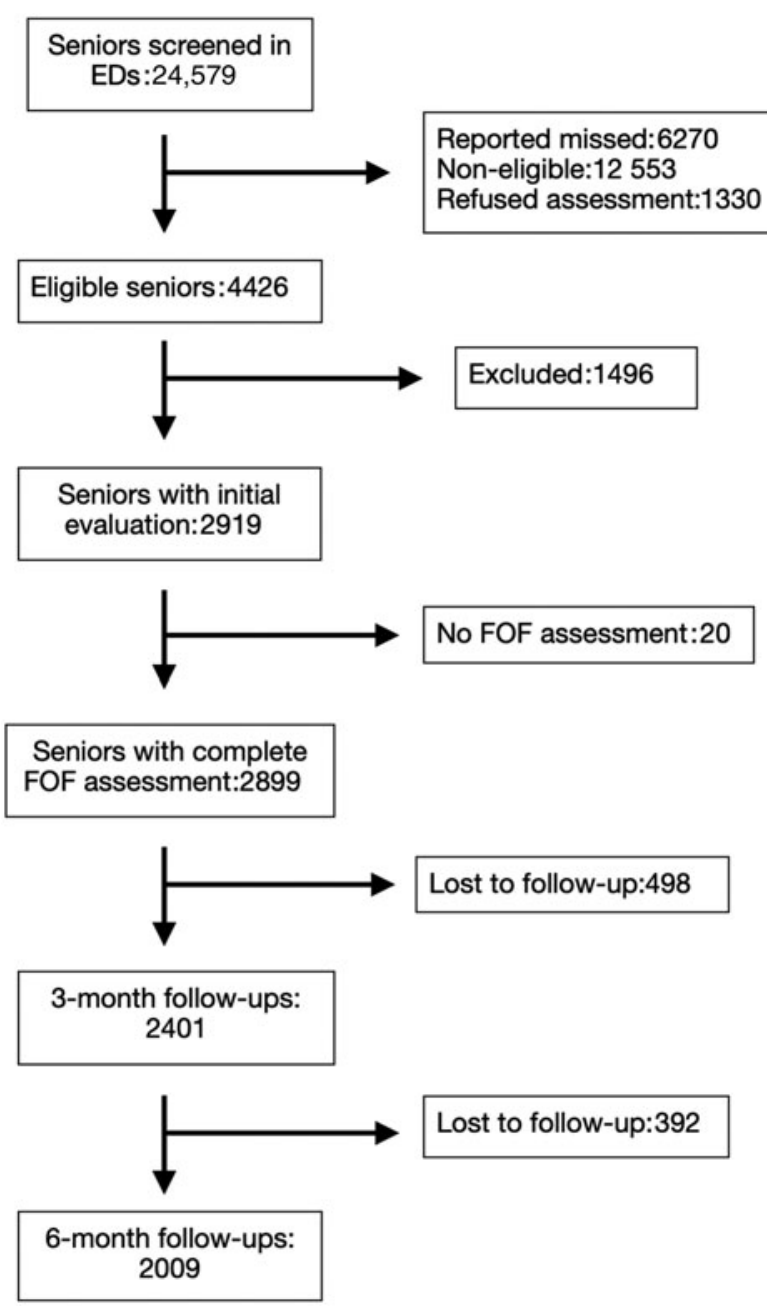

Figure 1. Study flow chart.

$E D=$ emergency department; FOF = fear of falling.

\section{Data analysis}

Descriptive statistics using the Student's t-test and the chisquare test (means, proportions) were used to describe patients' characteristics according to fear of falling levels. Logistic regressions were used to examine whether fear of falling alone predicted the outcomes (yes/no) at 3 and 6 months. The risk of return to the ED and falls according to fear of falling levels were estimated using odds ratios (OR, with 95\% confidence intervals [95\% CI]), using mild fear of falling as the reference. Predictive statistics with $95 \%$ CI were computed (sensitivity, specificity, predictive positive value $\left[\mathrm{PPV}_{-}\right.$and negative predictive value (NPV]). Sensitivity analyses were performed to determine the best (no return to the ED/fall) and worst (positive return to the $\mathrm{ED} /$ fall) case scenarios for the missing

\begin{tabular}{|c|c|c|}
\hline & $\begin{array}{l}\text { Participants } \\
\mathrm{N}=2009\end{array}$ & $\begin{array}{l}\text { Lost to follow-up } \\
\qquad \mathrm{N}=890\end{array}$ \\
\hline Short FES-I score /28, mean (SD) & $8.9(3.2)$ & $9.0(3.3)$ \\
\hline Age in years - mean (SD) & $76.2(7.5)$ & $76.6(7.8)$ \\
\hline Female & $65.6 \%$ & $64.2 \%$ \\
\hline No. of comorbidities - mean (SD) & $4.0(2.5)$ & $3.8(2.5)$ \\
\hline Cognitive impairments & $23.2 \%$ & $31.9 \%$ \\
\hline $0-1$ & $75.9 \%$ & $73.8 \%$ \\
\hline 2 and more & $24.1 \%$ & $26.2 \%$ \\
\hline OARS score/28, mean (SD) & $27.2(1.4)$ & $26.9(1.8)$ \\
\hline Self-reported anxiety & $12.4 \%$ & $12.5 \%$ \\
\hline Self-reported previous falls & $21.4 \%$ & $21.2 \%$ \\
\hline TUG test (seconds) mean (SD) & $13.9(9.7)$ & $13.7(7.0)$ \\
\hline 0 (robust) & $62.7 \%$ & $58.4 \%$ \\
\hline 1 (pre-frail) & $29.6 \%$ & $30.6 \%$ \\
\hline 2-3 (frail) & $7.7 \%$ & $11.0 \%$ \\
\hline Fall from own height & $65.4 \%$ & $65.2 \%$ \\
\hline Fall from higher & $12.3 \%$ & $12.2 \%$ \\
\hline Motor vehicle accident & $3.7 \%$ & $4.0 \%$ \\
\hline Other & $18.6 \%$ & $18.7 \%$ \\
\hline 1-8 (minor) & $99.0 \%$ & $99.2 \%$ \\
\hline 9-15 (moderate) & $1.0 \%$ & $0.8 \%$ \\
\hline 16 and more (severe) & $0 \%$ & $0 \%$ \\
\hline \multicolumn{3}{|c|}{$\begin{array}{l}\text { FES-I = Falls Efficacy Scale-International; ISAR = identification of seniors at risk; OARS = } \\
\text { Older American Resources Services-functional scale; } S O F=\text { study of osteoporotic } \\
\text { fractures; } S D=\text { standard deviation. }\end{array}$} \\
\hline
\end{tabular}

data. Statistical significance was defined as $p$-values $\leq$ 0.05 . Data were analysed using SAS software (SAS Institute, Inc., Cary, NC), version 9.4.

\section{RESULTS}

Baseline fear of falling data was available for 2,899 patients, and follow-up rates are shown in the study flow chart (Figure 1). Patients who were lost to follow-up were mostly similar to those with complete follow-ups, but a significant difference was found regarding cognitive impairment, with lost-to-follow-up patients being more cognitively impaired at baseline (see Table 1 for full details). Table 2 shows the participants' characteristics according to fear of falling levels. Patients with moderate to severe fear of falling were older, had more comorbidities, were more cognitive impaired, and experienced more self-reported anxiety. Patients with higher fear of falling were frailer, had a slower mobility (TUG test), and a higher rate of previous falls. 


\begin{tabular}{|c|c|c|c|}
\hline & $\begin{array}{c}\text { Mild FOF } \\
N=1871 \\
(64.5 \%)\end{array}$ & $\begin{array}{c}\text { Moderate } \\
\text { FOF } \\
N=751 \\
(25.9 \%)\end{array}$ & $\begin{array}{c}\text { Severe } \\
\text { FOF } \\
N=277 \\
(9.6 \%)\end{array}$ \\
\hline \multicolumn{4}{|l|}{ Age in years, $\mathrm{n}(\%)$} \\
\hline $65-74$ years & $937(50.1)$ & $271(36.1)$ & $112(40.4)$ \\
\hline $75-84$ years & $684(36.6)$ & $321(42.7)$ & 107 (38.6) \\
\hline $85+$ years & $250(13.4)$ & $159(21.2)$ & $58(20.9)$ \\
\hline Female n (\%) & $1146(61.3)$ & $537(71.6)$ & $204(73.7)$ \\
\hline \multicolumn{4}{|l|}{ Number of comorbidities, n (\%) } \\
\hline $0-1$ & $380(20.3)$ & $68(9.1)$ & $18(6.5)$ \\
\hline $2-4$ & $998(53.4)$ & $291(38.8)$ & $87(31.5)$ \\
\hline 5 and + & $492(26.3)$ & $391(52.1)$ & $171(62.0)$ \\
\hline Cognitive impairment, n (\%) & 423 (23.9) & $198(27.5)$ & 87 (33.3) \\
\hline \multicolumn{4}{|l|}{ ISAR score/6, n (\%) } \\
\hline $0-1$ & $1552(83.2)$ & $491(65.5)$ & $133(48.4)$ \\
\hline 2 and + & $314(16.8)$ & $259(34.5)$ & $142(51.6)$ \\
\hline OARS score/28, Mean \pm SD & $27.4 \pm 1.2$ & $26.8 \pm 1.7$ & $\begin{array}{c}25.9 \pm \\
2.2\end{array}$ \\
\hline Self-reported anxiety, n (\%) & $164(8.8)$ & $129(17.3)$ & $65(23.7)$ \\
\hline Previous falls, $\mathrm{n}(\%)$ & 297 (15.9) & 209 (27.9) & $110(40.0)$ \\
\hline \multicolumn{4}{|l|}{ Timed « Up and Go », n (\%) } \\
\hline Time $<10$ seconds & $167(35.2)$ & $31(17.9)$ & $3(6.0)$ \\
\hline Time 10-19 seconds & $268(56.5)$ & $104(60.1)$ & $23(46.0)$ \\
\hline Time $20-29$ seconds & $32(6.8)$ & $28(16.2)$ & $17(34.0)$ \\
\hline Time $>30$ seconds & $7(1.5)$ & $10(5.8)$ & $7(14.0)$ \\
\hline \multicolumn{4}{|l|}{ SOF frailty score, $\mathrm{n}(\%)$} \\
\hline 0 (robust) & 540 (68.9) & $159(53.5)$ & $26(26.0)$ \\
\hline 1 (pre-frail) & $209(26.7)$ & $97(32.7)$ & $48(48.0)$ \\
\hline 2-3 (frail) & $35(4.5)$ & $41(13.8)$ & $26(26.0)$ \\
\hline \multicolumn{4}{|l|}{ Mechanism of injury, n (\%) } \\
\hline Fall from own height & $1103(61.2)$ & $521(71.8)$ & $199(74.5)$ \\
\hline Fall from higher & $216(12.0)$ & $94(13.0)$ & $33(12.4)$ \\
\hline Motor vehicle accident & $84(4.7)$ & $16(2.2)$ & $7(2.6)$ \\
\hline Other & $399(22.1)$ & $95(13.1)$ & $28(10.5)$ \\
\hline \multicolumn{4}{|l|}{ Injury Severity Score, n (\%) } \\
\hline 1-8 (minor) & $1786(99.2)$ & 714 (98.9) & $262(98.9)$ \\
\hline 9-15 (moderate) & $15(0.8)$ & $8(1.1)$ & $3(1.1)$ \\
\hline 16 and more (severe) & 0 & 0 & 0 \\
\hline
\end{tabular}

Figure $2 \mathrm{a}$ and $2 \mathrm{~b}$ show the proportions and total numbers of falls and return to the ED according to fear of falling levels. While the total number of outcome events is greater in patients with mild fear of falling, the proportions of falls and return to the ED increased at 3 and 6 months with rising fear of falling levels at both time points (3-month falls in mild-fear of falling $=9.3 \%$ v. severe-fear of falling $=18.2 \% ; 3$-month return to the ED: mild-fear of falling $=12.0 \% \mathrm{v}$. severe fear of falling $=17.2 \%)$.
ORs were computed on the complete data set for both outcomes and time points according to fear of falling and ORs from the sensitivity analyses. Our results indicate that the risk of falls at 3 and 6 months significantly increased in both moderate (OR: 1.27 to 1.80 at 3 months, and 1.19 to 1.63 at 6 months) and severe (OR: 1.39 to 2.18 at 3 months, and 1.48 to 2.37 at 6 months) fear of falling groups. With regards to the risk of return to the ED, only severe fear of falling was associated with a significant increase of return to the ED at 3 


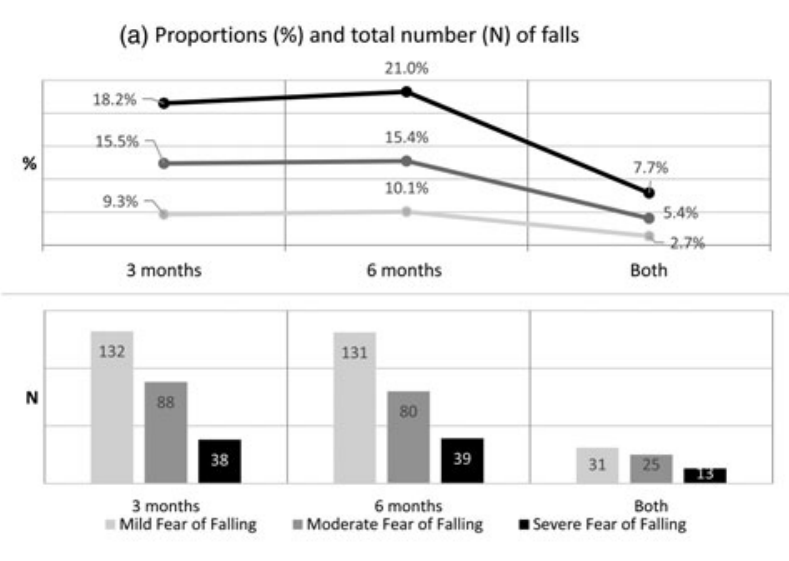

(b) Proportions (\%) and total number (N) of return to ED

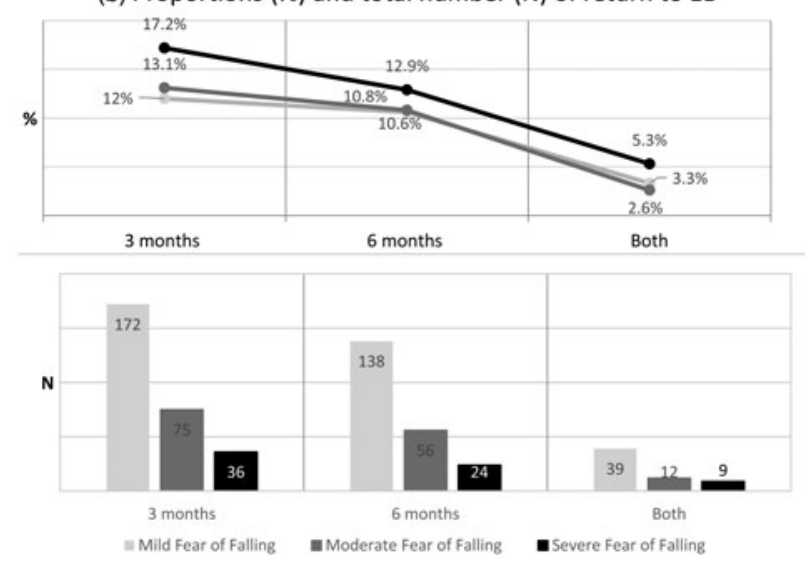

Figure 2. a) Proportion and number of patients with falls and b) unplanned return to ED at follow-up according to fear of falling levels at 3 months, 6 months, and both.

months (OR: 1.52, $p<0.05$ ) (full results are shown in Table 3). The predictive statistics of moderate and severe fear of falling levels considered together (v. mild fear of falling) for both outcomes at 6 months were also computed. Overall, the positive predictive capacities values of the fear of falling were low for return to the ED (sensitivity $=36.2 \%$; PPV: $7.7 \%$ to $39.3 \%$ ) and falls (sensitivity: $38.6 \%$ to $47.6 \%$; PPV: $11.6 \%$ to $43.1 \%$ ) (see Table 3 ).

Figure 3 shows the reasons for return to the ED based on medical chart reviews in a subsample of patients $(\mathrm{n}=71)$ from the study hub, the Hôpital de l'EnfantJésus, where $70 \%$ of return to the ED at 3 and 6 months were for medical reasons and $30 \%$ for traumatic reasons (i.e., missed injuries, delayed symptoms of concussion, etc.). Patients with mild to moderate fear of falling returned mostly for medical reasons $(76.1 \%$ and $81.3 \%$ in the mild and moderate fear of falling groups, respectively), whereas $77.8 \%$ return to the ED in patients with severe fear of falling were for traumatic reasons.

\section{DISCUSSION}

\section{Interpretation and previous studies}

This study shows that the risk of falls within 6 months after ED-visits for minor injuries by older adults significantly rises with their increasing fear of falling levels. This is consistent with previous evidence that fear of falling is associated with future falls. ${ }^{29,30}$ However, the significant increase in return to the ED at 3 months in severe fear of falling observed in the complete data was most likely due to the important loss to follow-up rate as it was not replicated in the sensitivity analyses. We also found that fear of falling alone tends to have poor predictive ability for both outcomes.

Overall, in our study, $12.8 \%$ and $10.9 \%$ of patients returned to EDs at 3 and 6 months, respectively. These cumulative incidences are somewhat less significant than previous reports, ${ }^{6,9,11}$ and this could be attributed to our loss to follow-up rate. The latter could also partially explain the lack of association between fear of falling and return to the ED. This could also have been cause by our smaller number of patients with moderate or severe fear of falling, which may have been insufficient to show a difference since $64 \%$ of our cohort had a mild fear of falling. With regards to fall rates, our results concur with those of similar studies. ${ }^{6}$ Our overall fall rates were $11.9 \%$ and $12.5 \%$ at 3 and 6 months, respectively, and only $3.8 \%$ fell at both time-points.

\section{Strengths and limitations}

There are limitations to this study. Firstly, return to the ED and falls were self-reported. As some of our patients had cognitive impairments, their reliability to recall and declare falls or return to the ED may have been limited. Moreover, patients may underreport such events, fearing that health professionals might consider them unfit to stay in their homes. Secondly, our loss to follow-up is significant, and patients lost to follow-up had poorer cognition and were frailer. This could have underestimated negative outcomes for patients. However, as sensitivity analyses showed, the association between fear of falling and future falls is not influenced by losses to follow-up. Finally, there was no analysis on the possible medical or psychological causes for fear of falling in our patients. With regards to this issue, in the pilot study $(n=335)$ of the CETI cohort, the Hospital Anxiety and Depression Scale (HADS) ${ }^{31}$ was used to evaluate 


\begin{tabular}{|c|c|c|c|c|}
\hline & \multicolumn{2}{|c|}{ Return to ED } & \multicolumn{2}{|c|}{ Future falls } \\
\hline & $\begin{array}{c}\text { Moderate FOF } \\
\text { OR }(95 \% \text { CI) }\end{array}$ & $\begin{array}{l}\text { Severe FOF } \\
\text { OR }(95 \% \mathrm{Cl})\end{array}$ & $\begin{array}{c}\text { Moderate FOF } \\
\text { OR }(95 \% \mathrm{CI})\end{array}$ & $\begin{array}{l}\text { Severe FOF } \\
\text { OR }(95 \% \mathrm{Cl})\end{array}$ \\
\hline \multicolumn{5}{|c|}{ Analyses with available data } \\
\hline 3-month & $1.11(0.83-1.48)$ & $1.52(1.03-2.26)$ & $1.80(1.35-2.41)$ & $2.18(1.47-3.23)$ \\
\hline 6-month & $1.03(0.74-1.42)$ & $1.25(0.79-1.99)$ & $1.63(1.21-2.20)$ & $2.37(1.59-3.52)$ \\
\hline Sensitivity* & $36.2 \%(29.6-43.0 \%)$ & & $47.6 \%(41.3-54.0 \%)$ & \\
\hline Specificity* & $65.3 \%(63.1-67.5 \%)$ & & $66.9 \%(64.6-69.1 \%)$ & \\
\hline$P P V^{*}$ & $11.3 \%(9.0-13.8 \%)$ & & $17.0 \%(14.3-20.0 \%)$ & \\
\hline PNV* & $89.4 \%(87.6-91.0 \%)$ & & $90.0 \%(88.2-91.5 \%)$ & \\
\hline \multicolumn{5}{|c|}{ Sensitivity analyses ${ }^{* *}$ (worst-case scenario) } \\
\hline 3-month & $1.05(0.88-1.25)$ & $1.24(0.95-1.61)$ & $1.27(1.07-1.52)$ & $1.39(1.07-1.81)$ \\
\hline 6-month & $1.04(0.87-1.23)$ & $1.18(0.91-1.52)$ & $1.19(1.00-1.41)$ & $1.48(1.15-1.90)$ \\
\hline Sensitivity* & $36.2 \%(33.4-39.2 \%)$ & & $38.6 \%(35.7-41.5 \%)$ & \\
\hline Specificity* & $65.3 \%(63.1-67.5 \%)$ & & $66.9 \%(64.6-69.1 \%)$ & \\
\hline PPV* & $39.3 \%(36.3-42.4 \%)$ & & $43.1 \%(40.0-46.2 \%)$ & \\
\hline PNV* & $62.4 \%(60.1-64.6 \%)$ & & $62.6 \%(60.3-64.8 \%)$ & \\
\hline \multicolumn{5}{|c|}{ Sensitivity analyses** (best-case scenario) } \\
\hline 3-month & $1.10(0.82-1.46)$ & $1.48(1.00-2.17)$ & $1.75(1.32-2.32)$ & $2.10(1.42-3.08)$ \\
\hline 6-month & $1.01(0.73-1.40)$ & $1.19(0.76-1.87)$ & $1.58(1.18-2.12)$ & $2.18(1.49-3.19)$ \\
\hline Sensitivity* & $36.2 \%(29.9-43.0 \%)$ & & $47.6 \%(41.3-54.0 \%)$ & \\
\hline Specificity* & $64.8 \%(62.9-66.6 \%)$ & & $65.9 \%(64.0-67.7 \%)$ & \\
\hline PPV* & $7.7 \%(6.2-9.5 \%)$ & & $11.6 \%(9.7-13.8 \%)$ & \\
\hline PNV* & $92.6 \%(91.3-93.7 \%)$ & & $83.3 \%(91.8-94.1 \%)$ & \\
\hline
\end{tabular}

patients' anxiety and depression. ${ }^{5}$ Given that HADS scores were highly correlated with self-reported anxiety, the HADS was removed from questionnaires. Pearson's correlation was high $(p<0.0001$, data not shown $)$

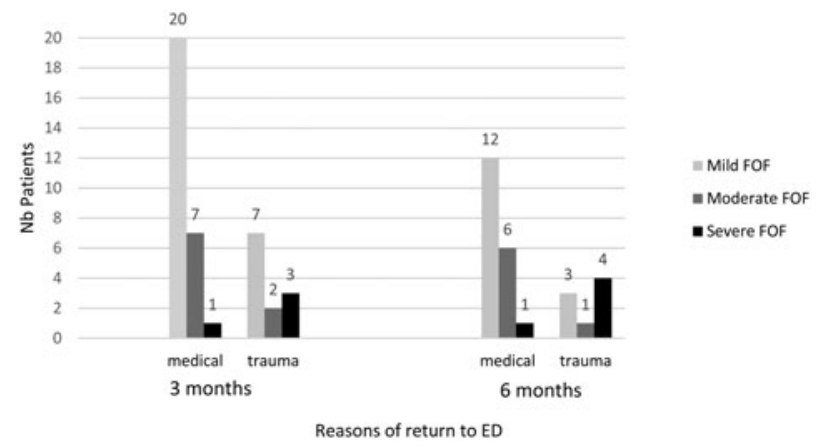

Figure 3. Reasons for return to the emergency department according to fear of falling (FOF) levels at 3 and 6 months among patients from Hôpital de l'Enfant-Jésus ( $n=40$ patients at 3 months; $n=27$ patients at 6 months). between fear of falling and HADS-anxiety scores in the subset of patients with both measures.

\section{Clinical implications}

Our results could be used to improve older patient care in the ED given the high rate of fear of falling in our participants. Indeed, many correlates of increased fear of falling, such as older age, repeated falls, numerous comorbidities or medications, impaired cognition, and function in daily life, ${ }^{32}$ are strong predictors of falls and of increased ED use. ${ }^{33,34}$ Moreover, these fear of falling correlates and fear of falling itself ${ }^{35}$ are strongly associated with frailty, which was shown to be a strong predictor of functional decline $e^{5}$ and of ED use ${ }^{36}$ after minor injuries in older adults. These factors can be assessed in older ED patients seeking care after a minor injury. Through their association with fear of falling, they can help physicians determine which older patients are at increased risk of returning to the ED 
and/or future falls. Those patients can then be oriented towards physical therapy services that can help improve their mobility and function ${ }^{37}$ and decrease their level of fear of falling. ${ }^{38-40}$

Interestingly, the medical chart reviews showed that patients with severe fear of falling, even if a smaller number, had more returns to the ED for trauma-related reasons. Therefore, it would be reasonable to believe that if fear of falling and its correlates were assessed in the ED, emergency physicians would be able to better identify patients at higher risk of subsequent falls, such as those with a severe fear of falling, and that this would translate into a decreased rate of ED returns by communitydwelling older adults.

\section{CONCLUSION}

This multicentre study described the characteristics of older patients suffering from mild, moderate, and severe fear of falling when consulting to the ED for minor injuries. The study showed that fear of falling alone is not a strong predictive factor for returning to the $\mathrm{ED}$ or future falls. However, fear of falling and its correlates can be identified in older ED patients, and this information could be useful to the emergency physician when planning post-ED resources and should be part of a comprehensive fall assessment.

\section{Competing interests}

None declared.

Acknowledgements: We would like to thank all of the emergency physicians and research assistants of all participating sites who made this project possible. This article received the following: Resident Abstract Award, CAEP 2019 (Halifax); AMUQ 2019 Poster Competition, 2nd place (Montréal); CIHR team grant top 6 projects, 2019.

\section{REFERENCES}

1. World Health Organization. Global health and aging. Geneva, Switzerland: WHO; 2011.

2. Masud T, Morris RO. Epidemiology of falls. Age Ageing 2001;30(Suppl 4):3-7.
3. Canadian Institute for Health Information. Highlights of 2010-2011 inpatient hospitalizations and emergency department visits. Ottawa (ON): CIHI; 2012.

4. Bernstein E. Repeat visits by elder emergency department patients: sentinel events. Acad Emerg Med 1997;4(6): 538-9.

5. Sirois MJ, Griffith L, Perry J, et al. Measuring frailty can help emergency departments identify independent seniors at risk of functional decline after minor injuries. 7 Gerontol A Biol Sci Med Sci 2017;72(1):68-74.

6. Foo CL, Siu VW, Tan TL, Ding YY, Seow E. Geriatric assessment and intervention in an emergency department observation unit reduced re-attendance and hospitalisation rates. Australas 7 Ageing 2012;31(1):40-6.

7. Lee J, Sirois MJ, Moore L, et al.. Return to the ED and hospitalisation following minor injuries among older persons treated in the emergency department: predictors among independent seniors within 6 months. Age Ageing 2015;44(4): 624-9.

8. Murphy SL, Dubin JA, Gill TM. The development of fear of falling among community-living older women: predisposing factors and subsequent fall events. 7 Gerontol A Biol Sci Med Sci 2003;58(10):M943-7.

9. Scheffer AC, Schuurmans MJ, van Dijk N, van der Hooft T, de Rooij SE. arconsequences among older persons. Age Ageing 2008;37(1):19-24.

10. Lavedan A, Viladrosa M, Jurschik P, et al.. Fear of falling in community-dwelling older adults: a cause of falls, a consequence, or both? PLoS One 2018;13(3): e0194967.

11. Murphy J, Isaacs B. The post-fall syndrome. A study of 36 elderly patients. Gerontology 1982;28(4):265-70.

12. Scheffer AC, van Hensbroek PB, van Dijk N, et al.. Risk factors associated with visiting or not visiting the accident \& emergency department after a fall. BMC Health Serv Res 2013;13:286.

13. Brousseau AA, Dent E, Hubbard R, et al. Identification of older adults with frailty in the emergency department using a frailty index: results from a multinational study. Age Ageing 2018;47(2):242-8.

14. Cinarli T, Koc Z. Fear and risk of falling, activities of daily living, and quality of life: assessment when older adults receive emergency department care. Nurs Res 2017;66 (4):330-5.

15. Provencher V, Sirois MJ, Ouellet MC, et al. Decline in activities of daily living after a visit to a Canadian emergency department for minor injuries in independent older adults: are frail older adults with cognitive impairment at greater risk? 7 Am Geriatr Soc 2015;63(5):860-8.

16. American College of Emergency Physicians. Geriatric emergency guidelines. Irving, TX: ACEP; 2013.

17. Kempen GI, Yardley L, van Haastregt JC, et al. The Short FES-I: a shortened version of the falls efficacy scale-international to assess fear of falling. Age Ageing 2008;37(1):45-50.

18. Canadian Study of Health and Aging Working Group. Canadian study of health and aging: study methods and prevalence of dementia. CMA7 1994;150(6):899-913. 
19. Daveluy C, Pica L, Audet R, Courtemanche F, Lapointe F. Enquête sociale et de santé 1998. Québec, Institut de la statistique; 2000.

20. McCusker J, Bellavance F, Cardin S, et al. Detection of older people at increased risk of adverse health outcomes after an emergency visit: the ISAR screening tool. 7 Am Geriatr Soc 1999;47(10):1229-37.

21. Association for the Advancement of Automotive Medicine. Abbreviated injury scale; 2015. Available at: https://www. aaam.org/abbreviated-injury-scale-ais (accessed March 10, 2020).

22. Copes WS, Champion HR, Sacco WJ, et al. The Injury Severity Score revisited. 7 Trauma 1988;28(1):69-77.

23. Bissett M, Cusick A, Lannin NA. Functional assessments utilised in emergency departments: a systematic review. Age Ageing 2013;42(2):163-72.

24. McCusker J, Bellavance F, Cardin S, Belzile E. Validity of an activities of daily living questionnaire among older patients in the emergency department. 7 Clin Epidemiol 1999;52(11):1023-30.

25. Eagles D, Perry JJ, Sirois MJ, et al. Timed Up and Go predicts functional decline in older patients presenting to the emergency department following minor trauma. Age Ageing 2017;46(2):214-8.

26. Kiely DK, Cupples LA, Lipsitz LA. Validation and comparison of two frailty indexes: The MOBILIZE Boston Study. 7 Am Geriatr Soc 2009;57(9):1532-9.

27. Luis CA, Keegan AP, Mullan M. Cross validation of the Montreal Cognitive Assessment in community dwelling older adults residing in the Southeastern US. Int 7 Geriatr Psychiatry 2009;24(2):197-201.

28. Knopman DS, Roberts RO, Geda YE, et al. Validation of the telephone interview for cognitive status-modified in subjects with normal cognition, mild cognitive impairment, or dementia. Neuroepidemiology 2010;34(1):34-42.

29. Friedman SM, Munoz B, West SK, Rubin GS, Fried LP. Falls and fear of falling: which comes first? A longitudinal prediction model suggests strategies for primary and secondary prevention. $\mathcal{F}$ Am Geriatr Soc 2002;50 (8):1329-35.

30. Legters K. Fear of falling. Phys Ther 2002;82(3):264-72.

31. Kumar A, Carpenter H, Morris R, Iliffe S, Kendrick D. Which factors are associated with fear of falling in communitydwelling older people? Age Ageing 2014;43(1):76-84.

32. Krieg C, Hudon C, Chouinard MC, Dufour I. Individual predictors of frequent emergency department use: a scoping review. BMC Health Serv Res 2016;16(1):594.

33. Neufeld E, Viau KA, Hirdes JP, Warry W. Predictors of frequent emergency department visits among rural older adults in Ontario using the Resident Assessment Instrument-Home Care. Aust 7 Rural Health 2016;24(2): $115-22$.

34. Esbri-Victor M, Huedo-Rodenas I, Lopez-Utiel M, et al. Frailty and fear of falling: the FISTAC study. 7 Frailty Aging 2017;6(3):136-40.

35. Fillion V, Sirois MJ, Gamache $\mathrm{P}$, et al. Frailty and health services use among Quebec seniors with non-hip fractures: a population-based study using administrative databases. BMC Health Serv Res 2019;19:70.

36. Martel D, Lauze M, Agnoux A, et al. Comparing the effects of a home-based exercise program using a gerontechnology to a community-based group exercise program on functional capacities in older adults after a minor injury. Exp Gerontol 2018;108:41-7.

37. Gammon K, ed. Physical therapist may ease fear of falling in the elderly. Los Angeles, CA: American Association for Geriatric Psychiatry; 2013.

38. Robinson JB, Wetherell JL. An interdisciplinary intervention for fear of falling: lessons learned from two case studies. Clin Gerontol 2018;41(4):366-73.

39. Kumar A, Delbaere K, Zijlstra GA, et al. Exercise for reducing fear of falling in older people living in the community: Cochrane systematic review and meta-analysis. Age Ageing 2016;45(3):345-52.

40. Zigmond AS, Snaith RP. The Hospital Anxiety and Depression Scale. Acta Psychiatr Scand 1983;67(6):361-70. 